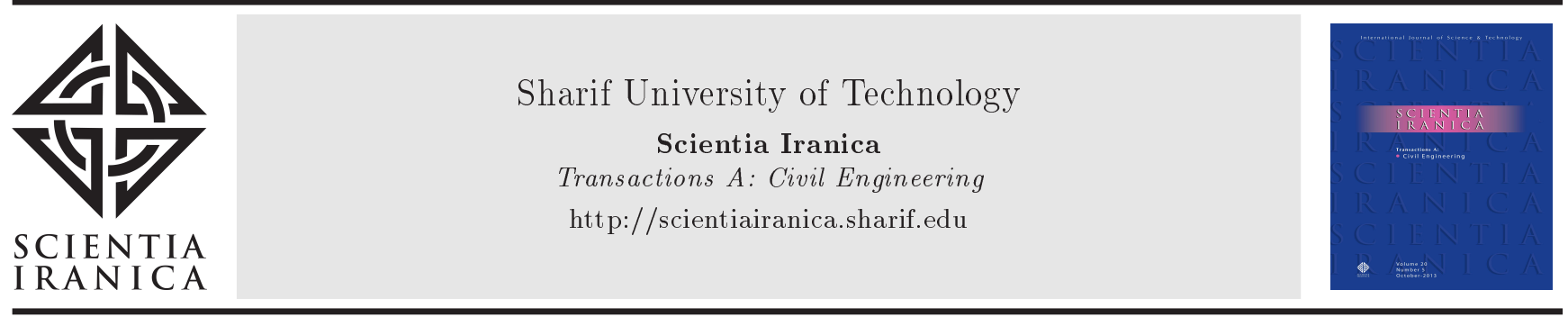

\title{
The effect of transportation and safety attitudes, personality, and lifestyle on vehicle type choice: A case study of Tehran
}

\author{
A. Mohammadi* and M. Kermanshah \\ Institute for Transportation Studies and Research (ITSR), Department of Civil Engineering, Sharif University of Technology (SUT), \\ Tehran, P.O. Box 11365-11155, Iran.
}

Received 4 December 2018; received in revised form 17 June 2019; accepted 10 August 2019

\section{KEYWORDS \\ Vehicle type choice; Subjective variables; Safety attitude; Factor analysis; Cluster analysis; Fuel economy level; Vehicle emission; Case study.}

\begin{abstract}
In recent years, researchers have paid particular attention to safety, air pollution, and energy consumption, which are all affected by vehicle type. The primary objective of this study is to achieve a thorough understanding of the relationships of transportation attitudes, safety attitudes, personality, and lifestyle with vehicle type for the first time in Iran, as a developing country. For this purpose, an interview questionnaire was designed, and 740 participants were interviewed in Tehran. Vehicle types are categorized into seven groups: mini, compact, medium, heavy, Sport Utility Vehicle (SUV), pickup, and motorcycle. In the first stage, factor analysis was employed to identify the latent variables regarding transportation attitudes, safety attitudes, personality, and lifestyle. In the second step, by using these latent variables, individuals were classified and a two-level clustering was formed. The correlation analysis performed in the third step showed a significant relationship between each category of people and the type of car. Likewise, the analyses carried out in this study revealed the significant relations between the vehicle type (classified based on fuel economy level, production country, vehicle emission, and vintage) and the attitudes of its owner. This information is beneficial to both vehicle manufacturers and transportation planners.
\end{abstract}

(C) 2021 Sharif University of Technology. All rights reserved.

\section{Introduction}

Previous studies have pointed to factors such as one's socio-economic status and built environmental features as the objective variables that can significantly affect transportation behavior; therefore, many researchers (e.g., [1-3]) have studied their effects on one's choice of vehicle type. According to new viewpoints suggested in social psychology for analyzing people's transportation

*. Corresponding author.

E-mail addresses: ali.mohammadi92@student.sharif.edu (A. Mohammadi); mkermanshah@sharif.edu (M. Kermanshah)

doi: $10.24200 /$ sci.2019.52402.2697 behavior in recent years, subjective variables such as attitudes, personality, and lifestyle of individuals give us a better insight rather than objective variables [4]. Therefore, people with a similar socio-economic status may differ in their behavioral paradigms. The main objective of this study is to identify the correlation of transportation attitudes, safety attitudes, personality, and lifestyle of individuals with their type of vehicle. In other words, this study attempts to find the answer to the following question: What type of car existing in the market do people from every walk of life choose (according to subjective variables)?

Experts in different fields are interested in identifying the factors that affect vehicle type choice and the reasons behind it. Vehicle manufacturers usually 
seek out the data and information on the status of their products in the market and the factors that affect them [5]. Also, it has been more than four decades that transportation experts have been studying the factors that affect one's choice of vehicle type [6]. Vehicle type is one of the factors that has the greatest effect on safety and accident damages [7], fuel consumption [8], and air pollution [9]. According to the statistics derived from Iran Legal Medicine Organization, in 2016, more than 16000 people were killed and approximately 333000 people were injured due to car accidents and motor vehicle collisions [10]; this amounts to two people per hour. In 2016, Iran was ranked as the tenth country in fuel consumption with use of about 270 million metric tons of oil equivalent [11]. Tehran, the capital city of Iran, was identified as the twenty-first pollutionemitting city in the world [12].

Further, due to better economic conditions and a greater diversity of vehicle types in developed countries, all such studies have been conducted in countries like the United States of America [13], Canada [14], Australia [15], Japan [16], Switzerland [17], etc. In recent years, Iran's development and economic growth has led to a better socio-economic status, which translated into a greater diversity of domestic vehicles. Our studies show that there are, currently, more than 500 kinds of cars with different features in Iran. In addition, this number is increasing per day considering the foreign vehicles imported in the market. It needs to be made clear that vehicles are characterized by too many differences in terms of safety, size, load weight and seating capacity, engine volume, fuel economy, pollution emission, and many other features.

Given the undeniable effect of many types of personal vehicles on environmental, energy, and health issues, it is of necessity to identify people's behavioral patterns across different regions so that customized and proper policymaking would be realized to reduce pollution, optimize fuel consumption, and reduce accident-induced damages. The present study makes its contribution in this regard by:

1. Focusing on the relations between vehicle types and subjective variables instead of objective variables;

2. Proposing a two-level clustering for car owners based on their attitudes, personalities, and lifestyles;

3. Classifying the vehicles according to different aspects such as size, fuel economy level, and vehicle emission;

4. Finding a significant correlation between drivers' viewpoints and type of their cars;

5. Studying the significance of vehicle type for the first time in a developing country like Iran.
In this work, a questionnaire was designed based on behavioral and cultural characteristics as well as the socio-cultural values of Iranian society. Seven hundred and sixty three vehicle owners in Tehran were interviewed, among which 740 questionnaires were filled out entirely in this study. According to the derived results, vehicles are divided into seven groups: mini, compact, medium, large, Sport Utility Vehicle (SUV), pickup, and motorcycle. It is worth mentioning that according to the proposed classification by Nationwide Personal Transportation Survey (NPTS) [18], motorcycle is considered a separate class of vehicle. Moreover, there are other vehicle classifications based on fuel economy level, manufacturing country, vehicle emission, vintage, and interviewer accident measurement that have been studied here.

The next section briefly describes previous studies on vehicle type choice. In the third section, the collected data and vehicle type classification are described. The fourth section is a brief review of the methodology of the study. The fifth section presents the results of analyzing transportation and safety attitudes, personality, and lifestyle and of classifying the individuals based on these factors. Next, the relations between different groups of individuals and their vehicle type are studied. The last section of this study discusses the results and offers a number of proposals for future studies.

\section{Literature review}

Type of vehicle has always been a subject of interest to policymakers since it is directly related to safety, pollution, and fuel consumption. Therefore, the earliest studies on this issue commenced in the 1970s, with the activities of Chamberlain [6], Lerner et al. [19], and Ayres et al. [20]. These studies that aimed to identify the factors affecting one's choice of a car based on size and function have been revisited and expanded by different researchers so far (e.g., in the 1980s, Manski and Sherman [21], Hocherman et al. [22], and Mannering and Winston [23]; in the 1990s, Golob et al. [24], McCarthy and Tay [1], and Wu et al. [25]; in the 2000s, Mohammadian and Miller [26], Bhat and Sen [27], and Spissu et al. [28]; and in the 2010s, Paleti et al. [29], Vyas et al. [30], and Liu et al. [3]). This historical process shows that over many years, the type of vehicle has always been an interesting subject for researchers.

In order to extract relevant information on choosing the type of vehicle from previous studies in line with the purpose of this research and available data, a group of independent variables including vehicle characteristics, household socio-economic factors, individual characteristics, employment, life cycle, built environment, and public transit characteristics was considered and analyzed. Because different vehicle 
classifications have been used in each study, it is difficult to compare significant independent variables. However, considerations show that the characteristics of vehicle and socio-economic factors of the household are the first and foremost noticeable variables in previous studies (e.g., [31-33]). Over time, with more accurate studies, individual characteristics, life cycle, and built environmental characteristics have been added to this group (e.g., [34-36]).

Choo and Mokhtarian [5] identified three logical reasons why others have paid insignificant attention to subjective variables. The first reason is that the time required for collecting data on such variables (attitudes) may last longer. Second, designing and analyzing such questionnaires require specific skills (e.g., familiarity with factor analysis). Third, there is no simple method to predict these subjective variables. Thus, it is not possible to predict the future demand of dependent variables. However, the third reason does not contradict the value of this study, because the use of these subjective variables gives a better understanding than that of only objective variables. Besides, these researchers are of the opinion that the concept of predicting attitudes without much efforts in this regard is quite futile [5].

Many different definitions on attitude have been provided so far and they all indicate that the role of attitudes is instrumental to the evaluation of some motives that affect the behavior of individuals [37]. Wu et al. [25] conducted one of the first studies in this field to identify the effect of attitudes and personality on vehicle type demand in the future. For this purpose, they used a stated preference dataset and accordingly, people selected their choices among three alternatives according to what is illustrated to them in the future. The alternatives are as follows:

1. Not to buy a car;

2. Mini-car;

3. Standard car.

The results show that both groups of factors (transportation attitudes and personality characteristics of individuals) are significant in choosing vehicle type.

Studies on the effect of lifestyle on travel behavior have been more restricted and are more recent than studies in psychology. One of the first studies on lifestyle that concentrated on comments and individual tendencies regarding problems related to household, work, and recreation is the study by Salomon and BenAkiva [38]. They defined a man's lifestyle with respect to household membership, employment, and orientation of leisure time while considering common restrictions. Before that, in line with other studies, lifestyle was described as a private and invisible subject and there have been attempts to illustrate lifestyle through a combination of socio-economic characteristics and living conditions [39]. Choo and Mokhtarian [5] studied the effects of one's attitude, personality, and lifestyle on vehicle type choice and showed how some of these factors affect people's choices. The result of the study shows that a frustrated lifestyle has a negative effect on choosing luxury cars and SUV. Researchers regard these kinds of vehicles as a demonstration of selfreliance and there is a little probability that depressed people will select this vehicle type. Furthermore, the lifestyle of workaholic people has a negative effect on choosing mini cars. Probably, such people earn better incomes and tend to use larger cars.

Unlike numerous studies devoted to investigating vehicle type choice with focus on objective variables, the main focus of this study is to explore the correlation between vehicle type and subjective variables such as attitudes, personality, and lifestyle. Moreover, this study is done in Iran and it is the first study on vehicle type in a developing country.

\section{Data}

\subsection{Questionnaire design}

The data used in this study include a questionnaire that contains questions about transportation attitudes, safety attitudes, personality, lifestyle, car information, accidents, household socio-economic information, personal characteristic, and life cycle. To design the questionnaire, many researches have been carried out. The designed questionnaire has been inspired from Choo and Mokhtarian [5] and Cao et al. [34] for transportation attitudes, Ulleberg and Rundmo [40], and Chen [41] for safety attitudes, NEO personality inventory [42], and Eysenck's personality inventory [43] for personality, and Redmond [44] and Mokhtarian et al. [45] for lifestyle question. Besides, there are some other questions mentioned in each case based on the domestic conditions and cultural features in Iran. Of note, the 5-point Likert-type scale (strongly disagree, disagree, neither agree nor disagree, agree, and strongly agree), which is one of the most common scales in psychology questionnaires, was used for each of questions in this survey.

\subsection{Survey and study area}

This study was conducted in the capital of Iran, Tehran, with a population of 8.7 million people distributed over a land area of 730 square kilometers, and it is the largest city in Iran [46]. Face-to-face interviews with car owners in Tehran were carried out to collect data by using a paper-based questionnaire featuring six pages. The interviews were conducted in collaboration with a team of postgraduates of transportation planning. These interviews were conducted in public places such as offices, shopping malls, gas 
stations, and parking lots with employees and visitors. The data were collected over a period of approximately one month in February 2018. Then, 763 individuals were surveyed, among whom 740 questionnaires were thoroughly completed and used for this study.

It should be noted that there is no information available about the number of vehicles for each type and their owners in Tehran. Therefore, it is not possible to compare the collected information with the population of car owners. Table 1 shows some personal information of the interviewees. In the collected sample, only $20 \%$ of interviewees were female given that there are a few Iranian women who own and drive cars.

Because only vehicle owners are included in the study, interviewees were between the ages of 18-71 years. In this study, with an average age of 35.7 years, the contribution of people between the ages of 18-24 years was less than the share of that age class in the population pyramid of Tehran [47] because of low incomes, not having financial independence, and the legal beginning age for vehicle ownership. In the collected databank, the average size of the household of interviewees was 3.71. According to the report of the Statistical Center of Iran in 2016, the average size of the household in Tehran province was 3.1 [47]. Because interviewees are all vehicle owners, increase in the size of the household in the collected samples of this study seems reasonable since some previous studies have shown that with an increase in the size

Table 1. Databank composition.

\begin{tabular}{|c|c|c|}
\hline Variable & Category & Percentage \\
\hline \multirow{3}{*}{ Gender } & Male & 79.6 \\
\hline & Female & 20.4 \\
\hline & Single & 54.0 \\
\hline \multirow{2}{*}{ Marital status } & Married & 44.2 \\
\hline & Divorced/widowed & 1.8 \\
\hline \multirow{5}{*}{ Age (years) } & $18-24$ & 18.7 \\
\hline & $25-30$ & 25.1 \\
\hline & $31-40$ & 31.2 \\
\hline & $41-50$ & 13.7 \\
\hline & $>51$ & 11.3 \\
\hline \multirow{5}{*}{ Education } & No academic degree & 4.8 \\
\hline & Diploma & 23.3 \\
\hline & Bachelor & 50.3 \\
\hline & Master & 19.8 \\
\hline & Doctoral & 1.8 \\
\hline
\end{tabular}

of a household, the probability of vehicle ownership increases [48].

\subsection{Car classification}

Section 5 of the questionnaire is aimed at gathering information about the household vehicle including number, name, type, producing company, purchase date, and the owner. Although some households own more than one car, the respondents were asked to answer the question with respect to their most used car. Besides, some other information like fuel economy and vehicle emission was collected through the official websites of the manufacturing companies. In addition to these considerations, more data about the number of car accidents and motor vehicle collisions were sought.

There are numerous car classifications based on size and function. Here, according to the relative frequency of existing vehicles in Iran, the proposed classifications of US Insurance Institute for Highway Safety [49], and NPTS [18], vehicles were classified based on their function and weight. Therefore, by using vehicle weight, existing vehicles in Iran were divided into the mini, compact, medium, and large; by using function, vehicles were divided into SUV, Pickup, and motorcycle. Table 2 shows the frequency of each type.

With a closer look into the relationship of transportation attitudes, safety attitudes, personality, and lifestyle with vehicle type, more classifications were also derived here based on vehicle emission, fuel economy level, vintage, and production country. Likewise, to classify the vehicles in terms of safety, our information was obtained from injury and damage accidents, because existing limitations hampered the attempts at accessing the safety information of domestic vehicles. These categories and the frequency of each variable are shown in Table 2. In this sample, the order of frequency of foreign cars is as follows: those produced by South Korea, Japan, China, Germany, France, Italy, United Kingdom, and America.

\section{Methodology}

The methodology employed here aims to determine the relations between a set of subjective variables and car type based on the proposed method by Dashtestaninejad et al. [50]; to this end, in the first stage of the study, factor analysis was applied to identify the latent factors in relation to transportation attitudes, safety attitudes, personality, and lifestyle. In the second stage, cluster analysis was applied to cluster individuals using the latent factors that were identified in the first stage. In the last stage, correlation analysis was applied to study the correlation between individuals and their car type. SPSS Statistics 24 was used for all data analyses. 
Table 2. Vehicle and driver classification.

\begin{tabular}{|c|c|c|c|}
\hline Variable & Category & Percentage & Definition \\
\hline \multirow{7}{*}{$\begin{array}{c}\text { Vehicle type } \\
\text { (based on weight and function) }\end{array}$} & Mini & 15.0 & Curb weight from 810 to $999 \mathrm{~kg}$ \\
\hline & Compact & 24.6 & Curb weight from 1000 to $1100 \mathrm{~kg}$ \\
\hline & Medium & 28.1 & Curb weight from 1101 to $1200 \mathrm{~kg}$ \\
\hline & Large & 13.2 & Curb weight $1201 \mathrm{~kg}$ and over \\
\hline & SUV & 6.8 & - \\
\hline & Pickup & 6.5 & - \\
\hline & Motorcycle & 5.8 & - \\
\hline \multirow{2}{*}{ Vehicle emission } & Low & 24.1 & European emission standards higher than Euro 3 \\
\hline & High & 75.9 & Others \\
\hline \multirow{2}{*}{ Vehicle consumption } & Low & 51.8 & Fuel consumption less than 7 liters per $100 \mathrm{~km}$ \\
\hline & High & 48.2 & Others \\
\hline \multirow{2}{*}{ Vehicle age } & New & 22.6 & Vehicle age less than 3 years \\
\hline & Old & 77.4 & Others \\
\hline \multirow{2}{*}{$\begin{array}{l}\text { Vehicle production } \\
\text { country }\end{array}$} & Iranian & 76.8 & Produced by Iran \\
\hline & Foreign & 23.2 & Others \\
\hline \multirow{2}{*}{ Driver damage accident } & Yes & 37.7 & Driver with damage accident experience \\
\hline & No & 62.3 & Driver without damage accident experience \\
\hline \multirow{2}{*}{ Driver injury accident } & Yes & 4.6 & Driver with injury accident experience \\
\hline & No & 95.4 & Driver without injury accident experience \\
\hline
\end{tabular}

\subsection{Factor analysis}

Exploratory factor analysis is used to simplify complicated data by describing them in line with the smaller number of latent variables (factors) [51]. This method consists of four main steps: adequacy of sampling, factor extraction, selecting the appropriate number of factors, and factor rotation. Typically, adequacy of sampling is assessed using the Kaiser-Meyer-Olkin (KMO) and Bartlett's test. Also, as a criterion for adequacy of sample size, Costello and Osborne [52] introduced an index (the number of survey to statements) by studying 303 research papers in this field. They showed that if this ratio was greater than 20 to 1 , better results from exploratory factor analysis would be obtained. In the other steps of exploratory factor analysis, a number of methods have been proposed. In the present study, a set of these methods was examined and no change in the results was observed. Finally, the results obtained from the principal component analysis for factor extraction, eigenvalue-greater-thanone rule and scree test for selecting the appropriate number of factors, and direct oblimin rotation for factor rotation were given. It should be noted that due to the correlation between attitudes, it is suggested that oblique rotation methods be used to improve the data structure [52].

\subsection{Cluster analysis}

Cluster analysis or clustering is a statistical method for classifying data or similar observations (including individuals, objects, or events) into different classes. By using this statistical method, data are classified according to their measure of relationship. Therefore, members of a cluster have the most similarity with each other and the least similarity with other clusters [53]. There are two main discussions in clustering: selection of the number of clusters and selection of similarity criterion between members. Different methods and algorithms have been suggested for cluster analysis. In this study, elbow method was employed to determine the number of clusters and the k-means algorithm was applied to cluster people according to the latent 
factors of attitudes, personality, and lifestyle (which were obtained from the previous section).

\subsection{Correlation analysis}

As the first study in Iran on vehicle type selection, the correlation analysis was used to identify the relationships between subjective variables and vehicle type. Correlation analysis represents one of the descriptive analysis methods used to study the type (positive/negative) and strength of the relationship (correlation coefficient) between variables, which do not imply the causality of variables. In this study, Spearman's correlation was used to measure the type and strength of association and Pearson's chi-square test was carried out to examine the association between each cluster of people (which have been verified in clustering analysis step) and their vehicle type. Figure 1 shows the structure of the proposed algorithm.

\section{Analysis and results}

In this section, the results of the study are presented. First, the results of factor analysis are explained, followed by the results of cluster analysis and the explanation of each cluster. At the end, the results of correlation analysis and the correlation between the groups of individuals and vehicle type are presented.

\subsection{Factor analysis results}

In the designed questionnaire, there are 11 statements for attitude toward transportation, 15 statements for attitude toward safety, 14 statements for personality, and 13 statements for identification of the lifestyle of individuals. Because the ratio of the number of questionnaires to the number of statements is more than 20 to 1 in all cases, the size of the collected sample is sufficient. Likewise, KMO value and significance of Bartlett's test were determined in all the cases, as are shown in the last line of Tables 3 to 7 . In all cases, the KMO value was larger than 0.6 and the significance of Bartlett's test was 0.000 .

Table 3 presents the factor analysis results of transportation attitudes. According to this table, four latent factors have been identified: pro-transit, timedissatisfied, pro-driving, and pro-government. Protransit attitude refers to those who tend to use public transit for many reasons, while pro-driving attitude points to those who are interested in driving. The results show that these two attitudes have a negative correlation with each other $(r=-0.243)$; in other words, those who are interested in using public transit are less interested in driving. Time-dissatisfied attitude refers to those who are more sensitive to and suffer from long travel time. For the first time, in this study, a new attitude was identified and named progovernment attitude. This attitude represents the view of some people toward the government. These people abdicate their social responsibilities and think that the government is the only organization that must solve social problems. According to the correlation part of Table 3 , this view has a negative correlation $(r=-0.145)$ with those who have pro-transit attitudes and also, a positive correlation $(r=0.146)$ with those who are interested in driving. The negative correlation between pro-government and pro-transit attitudes

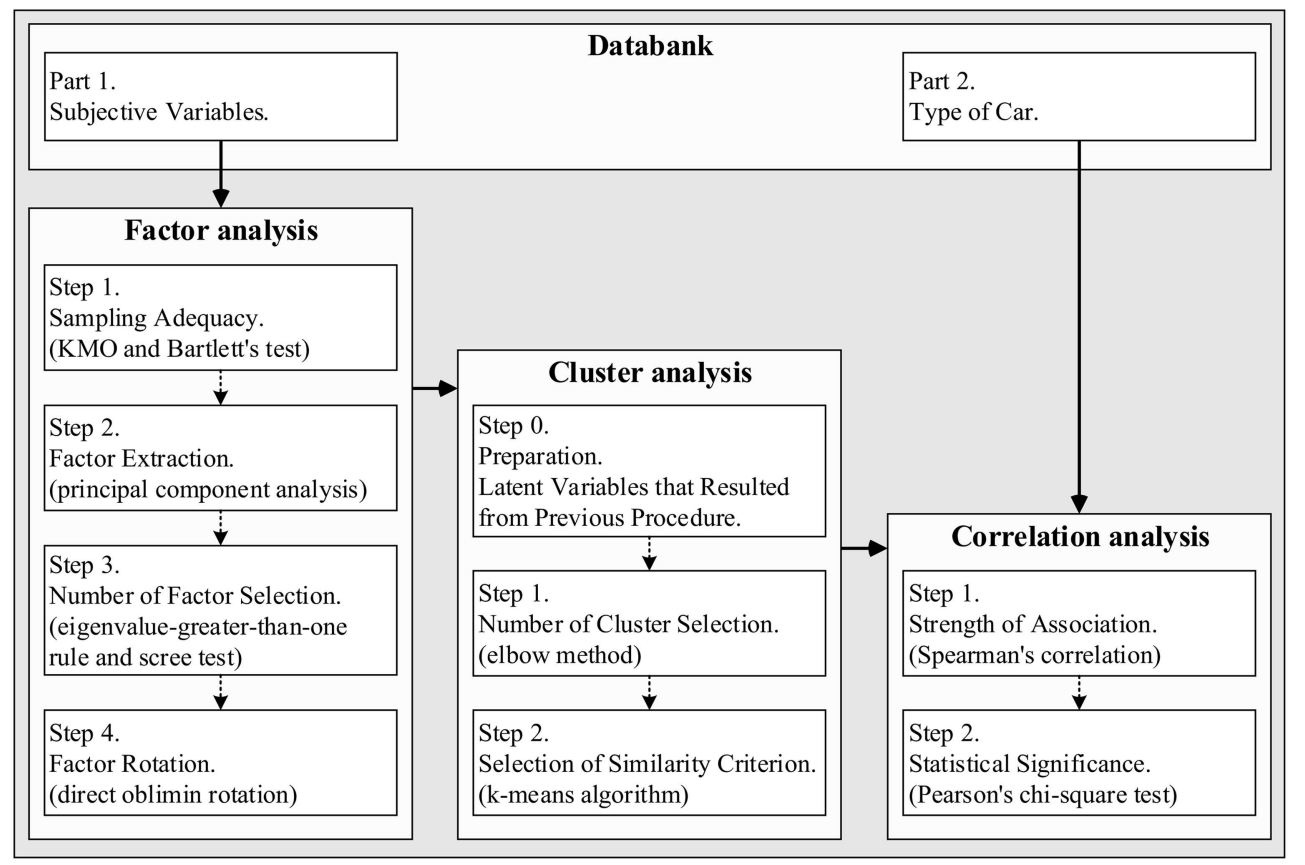

Figure 1. The structure of the proposed algorithm. 
Table 3. Pattern matrix for transportation attitudes

\begin{tabular}{|c|c|c|c|c|}
\hline \multirow{2}{*}{$\begin{array}{l}\text { Regarding transportation, state your agreement } \\
\text { with any of the following statements }\end{array}$} & \multicolumn{4}{|c|}{ Component } \\
\hline & $\begin{array}{c}\text { Pro- } \\
\text { transit }\end{array}$ & $\begin{array}{c}\text { Time- } \\
\text { dissatisfied }\end{array}$ & $\begin{array}{l}\text { Pro- } \\
\text { driving }\end{array}$ & $\begin{array}{c}\text { Pro- } \\
\text { government }\end{array}$ \\
\hline I am willing to use public transportation to reduce air pollution. & 0.839 & - & - & - \\
\hline I try to decrease my car usage to improve the air quality. & 0.818 & - & - & - \\
\hline $\begin{array}{l}\text { One of the reasons I use public transportation is } \\
\text { to get rid of the troubles related to car usage. }\end{array}$ & 0.608 & - & - & - \\
\hline I am used to my car and life would be hard without it. & -0.552 & - & - & - \\
\hline I believe that car usage is the best means of transportation. & -0.535 & - & - & - \\
\hline The long travel time to the destination highly annoys me. & - & 0.796 & - & - \\
\hline Being stuck in a heavy traffic makes me nervous. & - & 0.795 & & - \\
\hline I am not interested in driving. & - & - & -0.851 & - \\
\hline Driving is one of my hobbies. & - & - & 0.823 & - \\
\hline The main cause of most car accidents is the low quality of cars. & - & - & - & 0.755 \\
\hline $\begin{array}{l}\text { Only the government and car factories are responsible for reducing } \\
\text { air pollution. }\end{array}$ & - & - & - & 0.722 \\
\hline \multicolumn{5}{|c|}{ Component correlation $(r)$} \\
\hline Pro-transit & 1.000 & - & - & - \\
\hline Time-dissatisfied & $0.089^{*}$ & 1.000 & - & - \\
\hline Pro-driving & $-0.243^{* *}$ & -0.010 & 1.000 & - \\
\hline Pro-government & $-0.145^{* *}$ & $0.080^{*}$ & $0.146^{* *}$ & 1.000 \\
\hline $\mathrm{KMO}=0.746$ & \multicolumn{4}{|c|}{ Sig. of Bartlett's test $=0.000$} \\
\hline
\end{tabular}

*Correlation is significant at the 0.05 level (2-tailed); ** Correlation is significant at the 0.01 level (2-tailed).

means that those who are trying to be responsible for solving social problems tend to use public transit more and conversely, the positive correlation between progovernment and pro-driving attitudes means that prodriving people are careless about the problems caused by vehicles such as fuel consumption and air pollution.

Table 4 shows the results of exploratory factor analysis of the attitudes of individuals towards safety. As observed in the table, four attitudes have been identified: pro-risk, pro-negligence, pro-law, and promotorcycle. In this study, pro-risk attitude refers to individuals who tend to drive with higher speed and venturesome acts, such as overtaking on the right; likewise, pro-negligence attitude refers to drivers who neglect some safety acts such as fastening the seatbelt and safe distance control with the front vehicle. As expected, these two views have a positive $(r=0.325)$ and considerable correlation with each other. Pro-law attitude is the third view that was identified in this field. This attitude refers to those who believe in rigid enforcement of the law to achieve collision reduction and ensure greater safety. As observed in the factor correlation section, the pro-law attitude has a negative correlation with both pro-risk $(r=-0.232)$ and pronegligence $(r=-0.120)$ attitudes. The last attitude refers to those who believe that motorcycle is the best mode of transportation. According to Table 4, this attitude has a positive correlation with both pro-risk $(r=0.170)$ and pro-negligence $(r=0.219)$ attitudes.

The personality of interviewees was also studied and analyzed by exploratory factor analysis. According to Table 5, six types of personalities were identified: showy, social, patient, adventurer, procrastinator, and conservative. With respect to the correlation between factors, showy personality has a positive correlation with procrastinator personality $(r=0.100)$ and a negative correlation with conservative personality $(r=$ $-0.099)$. In other words, those who are interested in attracting people's attention procrastinate more and talk about their achievements in the public more than others. Another significant correlation in this section is the negative correlation between procrastinator and patient personalities $(r=-0.154)$. The negative correlation means that patient and quiet individuals are 
Table 4. Pattern matrix for safety attitudes.

\begin{tabular}{|c|c|c|c|c|}
\hline \multirow[b]{2}{*}{$\begin{array}{l}\text { Regarding safety, state your agreement with } \\
\text { any of the following statements }\end{array}$} & \multicolumn{4}{|c|}{ Component } \\
\hline & $\begin{array}{l}\text { Pro- } \\
\text { risk }\end{array}$ & $\begin{array}{c}\text { Pro- } \\
\text { negligence }\end{array}$ & $\begin{array}{l}\text { Pro- } \\
\text { law }\end{array}$ & $\begin{array}{c}\text { Pro- } \\
\text { motorcycle }\end{array}$ \\
\hline $\begin{array}{l}\text { I think it would be alright to drive at a speed higher } \\
\text { than the speed limits if the traffic flow permits. }\end{array}$ & 0.833 & - & - & - \\
\hline $\begin{array}{l}\text { It will be no problem driving over the speed limit } \\
\text { if I have a high driving skill. }\end{array}$ & 0.752 & - & - & - \\
\hline Driving at high speed is one of my hobbies. & 0.734 & - & - & - \\
\hline $\begin{array}{l}\text { Sometimes, it is necessary not to follow traffic } \\
\text { rules to arrive at my destination in time. }\end{array}$ & 0.697 & - & - & - \\
\hline $\begin{array}{l}\text { When the car in front is driving with a low speed, } \\
\text { we can overtake the car on the right side. }\end{array}$ & 0.581 & - & - & - \\
\hline $\begin{array}{l}\text { I always obey the traffic rules even if } \\
\text { there is no police enforcement. }\end{array}$ & -0.529 & - & - & - \\
\hline $\begin{array}{l}\text { I believe there is no need to fasten } \\
\text { seatbelt in urban routes. }\end{array}$ & - & 0.756 & - & - \\
\hline Experienced drivers do not need to fasten their seatbelts. & - & 0.688 & - & - \\
\hline The risk of death in crashes is very low, so caution can be ignored. & - & 0.665 & - & - \\
\hline Driving short distances also require the seatbelt to be fastened. & - & -0.590 & - & - \\
\hline $\begin{array}{l}\text { I believe it is very important to keep the safe distance } \\
\text { from the front car while driving. }\end{array}$ & - & -0.560 & - & - \\
\hline If driving laws are much tougher, many crashes will be prevented. & - & - & 0.828 & - \\
\hline $\begin{array}{l}\text { There should be severe penalties for drivers who } \\
\text { violate the speed limits (even for a } 10 \mathrm{~km} / \mathrm{h} \text { more). }\end{array}$ & - & - & 0.723 & - \\
\hline Motorcycles have low safety and it is not logical to ride them. & - & - & - & -0.847 \\
\hline I believe that the best mode of transportation is motorcycle. & - & - & - & 0.795 \\
\hline Component correlati & n $(r)$ & & & \\
\hline Pro-risk & 1.000 & - & - & \\
\hline Pro-negligence & $0.325^{* *}$ & 1.000 & - & - \\
\hline Pro-law & $-0.232^{* *}$ & $-0.120^{* *}$ & 1.000 & - \\
\hline Pro-motorcycle & $0.170^{* *}$ & $0.219^{* *}$ & -0.009 & 1.000 \\
\hline $\mathrm{KMO}=0.829$ & Sig. of $\mathrm{Ba}$ & lett's test $=$ & .000 & \\
\hline
\end{tabular}

* Correlation is significant at the 0.05 level (2-tailed). ** Correlation is significant at the 0.01 level (2-tailed).

better in management and are usually more punctual in doing their tasks.

Among the thirteen statements for the measurement of lifestyle, five latent factors were identified based on the eigenvalue-greater-than-one rule and scree test (Table 6). On the one hand, there are five factors that satisfy the first rule and are characterized by an eigenvalue value greater than one. On the other hand, in the chart of scree test, the point of five factors is the breaking point of the plot. These factors include lively, pro-sumptuous, unhealthy, unsociable, and workaholic. The pro-sumptuous are those interested in luxury and pricy goods and unsociable lifestyle means not having the tendency for participation in the society or even in family and friends' gatherings. As shown in Table 6, a lively lifestyle has a negative correlation with prosumptuous, unhealthy, and unsociable lifestyles, while it only has a positive correlation with workaholic 
Table 5. Pattern matrix for personalities.

\begin{tabular}{|c|c|c|c|c|c|c|}
\hline \multirow{2}{*}{$\begin{array}{c}\text { State your agreement } \\
\text { with any of the following statements. }\end{array}$} & \multicolumn{6}{|c|}{ Component } \\
\hline & Showy & Social & Patient & Adventurer & Procrastinator & Conservative \\
\hline I will be distinguished from others by having a nice car. & 0.654 & - & - & - & - & - \\
\hline I am a person who seeks variety. & 0.625 & - & - & - & - & - \\
\hline I am afraid of being jinxed by someone. & 0.614 & - & - & - & - & - \\
\hline I would like to be alone at my leisure times. & - & -0.782 & - & - & - & - \\
\hline We usually have outdoor fun collectively with others. & - & 0.723 & - & - & - & - \\
\hline I behave calmly to get my rights back. & - & - & 0.845 & - & - & - \\
\hline I am a patient person. & - & - & 0.808 & - & - & - \\
\hline $\begin{array}{l}\text { I love the excitement that usually rises while } \\
\text { riding a Ferris wheel or having thrill activities. }\end{array}$ & - & - & - & 0.798 & - & - \\
\hline Compared to others, I am afraid of fewer things. & - & - & - & 0.589 & - & - \\
\hline $\begin{array}{l}\text { Taking the responsibility of leading or } \\
\text { managing a situation is not easy for me. }\end{array}$ & - & - & - & - & 0.674 & - \\
\hline I am a punctual and disciplined person. & - & - & - & - & -0.661 & - \\
\hline I waste a lot of time before starting work. & - & - & - & - & 0.578 & - \\
\hline I would like to tell others about my achievements. & - & - & - & - & - & -0.780 \\
\hline I trust others at a glance. & - & - & - & - & - & -0.701 \\
\hline \multicolumn{7}{|c|}{ Component correlation $(r)$} \\
\hline Showy & 1.000 & - & - & - & - & - \\
\hline Social & -0.038 & 1.000 & - & - & - & - \\
\hline Patient & -0.063 & 0.049 & 1.000 & - & - & - \\
\hline Adventurer & 0.019 & -0.005 & -0.070 & 1.000 & - & - \\
\hline Procrastinator & $0.100^{* *}$ & -0.056 & $-0.154^{* *}$ & $-0.091^{*}$ & 1.000 & - \\
\hline Conservative & $-0.099^{* *}$ & 0.028 & $0.076^{*}$ & $-0.078^{*}$ & -0.051 & 1.000 \\
\hline $\mathrm{KMO}=0.603$ & \multicolumn{6}{|c|}{ Sig. of Bartlett's test $=0.000$} \\
\hline
\end{tabular}

*Correlation is significant at the 0.05 level (2-tailed); ** Correlation is significant at the 0.01 level (2-tailed).

Table 6. Pattern matrix for lifestyles.

\begin{tabular}{|c|c|c|c|c|c|}
\hline \multirow{2}{*}{$\begin{array}{l}\text { State your agreement with any of } \\
\text { the following statements }\end{array}$} & \multicolumn{5}{|c|}{ Component } \\
\hline & Lively & Pro-sumptuous & Unhealthy & Unsociable & Workaholic \\
\hline I often feel I have no control over my life. & -0.767 & - & - & - & - \\
\hline Life sometimes seems desperate and gloomy to me. & -0.732 & - & - & - & - \\
\hline I am satisfied with my life overall. & 0.630 & - & - & - & - \\
\hline I often participate in social activities. & 0.467 & - & - & - & - \\
\hline I will always buy the most expensive stuff if I can afford it. & - & 0.882 & - & - & - \\
\hline I enjoy having luxury appliances and brand clothes. & - & 0.843 & - & - & - \\
\hline I usually follow my sports schedule on a regular basis. & - & - & -0.906 & - & - \\
\hline I have no sports activities during the week. & - & - & 0.866 & - & - \\
\hline I spend most of my time with friends and family. & - & - & - & -0.744 & - \\
\hline I always go outdoors on weekends to have fun. & - & - & - & -0.690 & - \\
\hline I usually do not go outdoors for fun on weekdays. & - & - & - & 0.554 & - \\
\hline I would like to assign most of my time to work. & - & - & - & - & 0.794 \\
\hline If I have enough money, I am no longer interested in my job. & - & - & - & - & -0.589 \\
\hline \multicolumn{6}{|c|}{ Component correlation $(r)$} \\
\hline Lively & 1.000 & - & - & - & - \\
\hline Pro-sumptuous & $-0.104^{* *}$ & 1.000 & - & - & - \\
\hline Unhealthy & $-0.235^{* *}$ & -0.008 & 1.000 & - & - \\
\hline Unsociable & $-0.130^{* *}$ & -0.068 & $0.165^{* *}$ & 1.000 & - \\
\hline Workaholic & $0.112^{* *}$ & -0.012 & 0.007 & -0.040 & 1.000 \\
\hline $\mathrm{KMO}=0.637$ & \multicolumn{5}{|c|}{ Sig. of Bartlett's test $=0.000$} \\
\hline
\end{tabular}

*Correlation is significant at the 0.05 level (2-tailed). **Correlation is significant at the 0.01 level (2-tailed). 
lifestyle; in other words, workaholic people are more lively and satisfied with their lives than others; also, unsociable people are less interested in sports activities and health $(r=0.165)$.

\subsection{Clustering}

As mentioned earlier, the relation between latent variables and vehicle type is identified by cluster analysis. For this purpose, by using elbow method, the case study analysis was divided into two main (and almost equal) clusters: risk-oriented and safety-oriented. The clustering results are shown in Table 7 . The numbers in each column of the table indicate the factor scores of each Cluster Center (CC) and in each section of transportation attitudes, safety attitudes, personality, and lifestyle, the main factor in each cluster (which has the biggest absolute value of numbers) is shown in boldface. According to Table 7, pro-transit attitude, pro-risk attitude, patient personality, and lively lifestyle were the main factors that yielded this classification. Among them, pro-risk attitude (with the highest rank) is the factor that caused the most significant difference between these two groups $(0.638$ and -0.585$)$. Therefore, these two clusters included risk-oriented and safety-oriented ones.

Given the generality of the clustering and to show the effect of the other factors in the classification, the individuals of each cluster were divided into sub- clusters by the k-means method. In the new clustering, risk-oriented people were divided into four sub-clusters and safety-oriented people were divided into three subclusters. The results of clustering are shown in Table 8 .

As shown in Table 8, the pro-risk attitude is positive in all the sub-clusters of risk-oriented people and is negative in all the sub-clusters of safety-oriented people. In Table 8, the main features (the largest absolute value of numbers) of transportation attitude, safety attitude, personality, and lifestyle are shown in boldface, and the largest number of each sub-cluster (which demonstrates the main feature of each subcluster) is used for naming the clusters. Therefore, risk-oriented people are divided into four sub-clusters:

1. Depression-oriented;

2. Motorcycle-oriented;

3. Danger-oriented;

4. Driving-oriented.

Safety-oriented people are divided into three subclusters:

1. Work-oriented;

2. Transit-oriented;

3. Vitality-oriented.

These sub-clusters are described in the following.

Table 7. Main cluster centers.

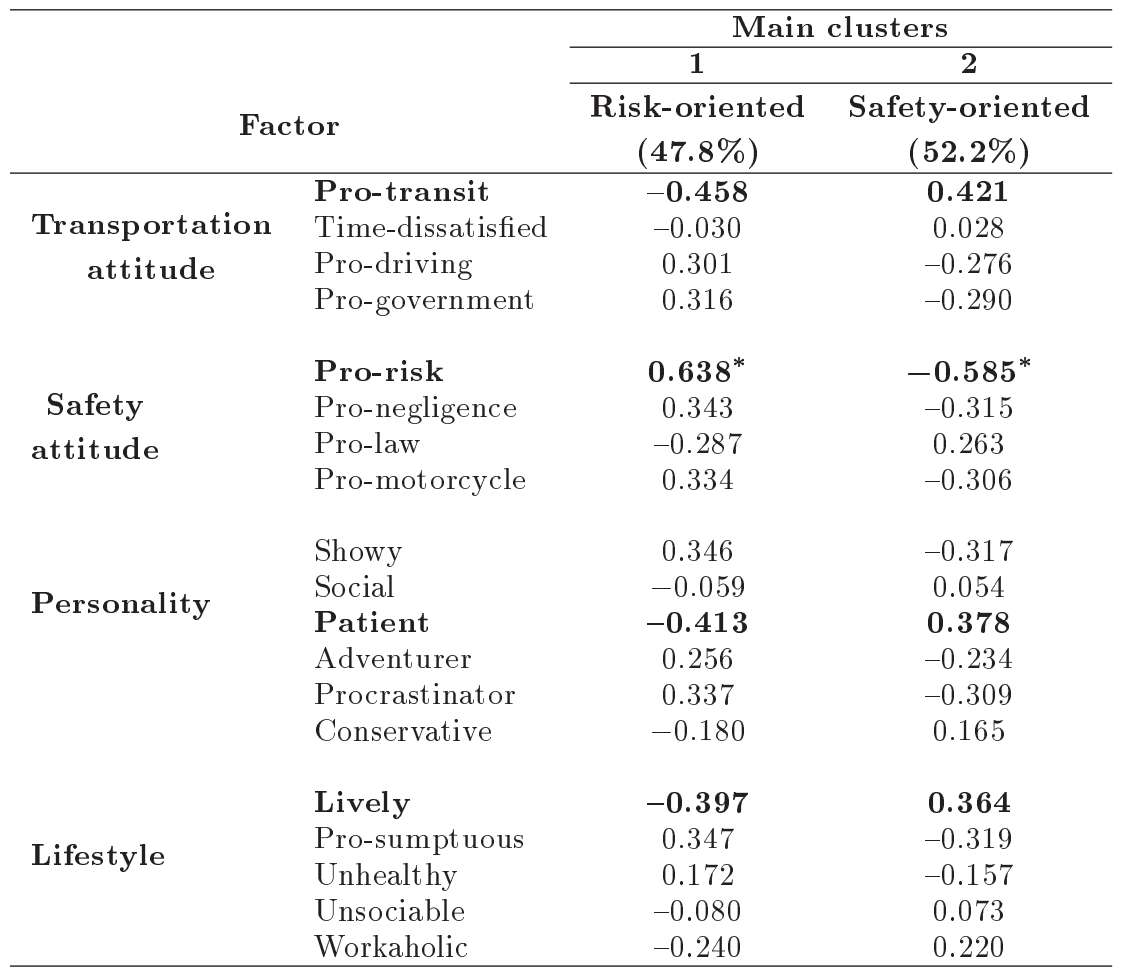

Note: The numbers in parentheses represent the percentage of cases in each

cluster. The main factors in each cluster are shown in boldface.

* The main feature is used for naming clusters. 
Table 8. Sub-cluster centers.

\begin{tabular}{|c|c|c|c|c|c|c|c|c|}
\hline \multirow{3}{*}{ Factor } & & \multicolumn{4}{|c|}{ Sub-Clusters } & \multirow[b]{2}{*}{2.1} & \multirow[b]{2}{*}{2.2} & \multirow[b]{2}{*}{2.3} \\
\hline & & 1.1 & 1.2 & 1.3 & 1.4 & & & \\
\hline & & $\begin{array}{c}\text { Depression- } \\
\text { oriented } \\
(13.2 \%)\end{array}$ & $\begin{array}{c}\text { Motorcycle- } \\
\text { oriented } \\
(10.7 \%)\end{array}$ & $\begin{array}{c}\text { Danger- } \\
\text { oriented } \\
(12.2 \%)\end{array}$ & $\begin{array}{c}\text { Driving- } \\
\text { oriented } \\
(11.8 \%)\end{array}$ & $\begin{array}{c}\text { Work- } \\
\text { oriented } \\
(16.9 \%)\end{array}$ & $\begin{array}{c}\text { Transit- } \\
\text { oriented } \\
(18.4 \%)\end{array}$ & $\begin{array}{c}\text { Vitality- } \\
\text { oriented } \\
(16.9 \%)\end{array}$ \\
\hline \multirow{4}{*}{$\begin{array}{c}\text { Transportation } \\
\text { attitude }\end{array}$} & Pro-transit & -0.351 & -0.088 & -0.865 & -0.494 & 0.263 & 0.436 & 0.562 \\
\hline & Time-dissatisfied & 0.523 & -0.885 & 0.126 & -0.040 & 0.409 & 0.038 & -0.365 \\
\hline & Pro-driving & -0.134 & -0.136 & 0.635 & $0.843^{*}$ & 0.168 & $-0.716^{*}$ & -0.242 \\
\hline & Pro-government & 0.376 & 0.166 & -0.087 & 0.801 & -0.011 & -0.314 & -0.543 \\
\hline \multirow{4}{*}{$\begin{array}{l}\text { Safety } \\
\text { attitude }\end{array}$} & Pro-risk & 0.433 & 0.431 & $0.940^{*}$ & 0.743 & -0.564 & -0.523 & -0.673 \\
\hline & Pro-negligence & 0.232 & 1.077 & 0.259 & -0.111 & -0.431 & -0.014 & -0.526 \\
\hline & Pro-law & -0.013 & -0.173 & -0.858 & -0.110 & 0.581 & 0.087 & 0.138 \\
\hline & Pro-motorcycle & 0.309 & $1.183^{*}$ & -0.043 & -0.019 & -0.406 & -0.307 & -0.206 \\
\hline \multirow{6}{*}{ Personality } & Showy & 0.763 & -0.040 & -0.121 & 0.709 & 0.283 & -0.601 & -0.608 \\
\hline & Social & -0.467 & -0.014 & 0.265 & 0.026 & 0.324 & -0.450 & 0.331 \\
\hline & Patient & -0.552 & -0.344 & -0.899 & 0.185 & 0.459 & 0.129 & 0.570 \\
\hline & Adventurer & -0.048 & 0.070 & 0.446 & 0.569 & -0.518 & -0.396 & 0.225 \\
\hline & Procrastinator & 0.627 & 0.774 & 0.101 & -0.143 & -0.180 & 0.048 & -0.826 \\
\hline & Conservative & -0.295 & -0.424 & 0.279 & -0.302 & 0.087 & 0.381 & 0.008 \\
\hline \multirow{5}{*}{ Lifestyle } & Lively & $-1.016^{*}$ & -0.469 & -0.276 & 0.242 & 0.175 & -0.064 & $1.017^{*}$ \\
\hline & Pro-sumptuous & 0.413 & -0.036 & 0.149 & 0.827 & 0.408 & -0.581 & -0.759 \\
\hline & Unhealthy & 0.792 & -0.056 & 0.153 & -0.302 & -0.340 & 0.151 & -0.311 \\
\hline & Unsociable & 0.632 & 0.191 & -0.720 & -0.465 & -0.258 & 0.626 & -0.198 \\
\hline & Workaholic & -0.087 & -0.651 & -0.409 & 0.134 & $0.595^{*}$ & -0.021 & 0.109 \\
\hline
\end{tabular}

Note: The numbers in parentheses represent the percentage of cases in each sub-cluster. The main factors in each sub-cluster are shown in boldface.

* The main feature is used for naming sub-clusters.

According to Table 8, depression-oriented people, which are the first sub-cluster of risk-oriented people, have a very less lively lifestyle $(C C=-1.016)$ and time-dissatisfied attitude $(C C=0.523)$ and showy personality $(C C=0.763)$ are the main features of this sub-cluster. Having a showy personality means that people of this sub-cluster tend to be seen more in the society. Moreover, depression-oriented people have procrastinator personality $(C C=0.627)$ and are less patient $(C C=-0.552)$. Unhealthy $(C C=0.792)$ and unsociable $(C C=0.632)$ lifestyles are the other features of this sub-cluster.

The main features of motorcycle-oriented people are as follows:

1. Pro-motorcycle attitude $(C C=1.183)$;

2. Procrastinator personality $(C C=0.774)$;
3. Not having time-dissatisfied attitude ( $C C=$ $-0.885)$;

4. Not having workaholic lifestyle $(C C=-0.651)$.

Moreover, motorcycle-oriented people have a highly pro-negligent attitude $(C C=1.077)$.

As mentioned earlier, pro-risk attitudes can be seen in every sub-cluster of the risk-oriented people. Nevertheless, pro-risk attitude is the main feature (the largest absolute value of numbers) of the third subcluster of pro-risk people, called pro-danger people. Other main features of this sub-cluster are nonexistence of pro-transit attitude $(C C=-0.865)$, patient personality $(C C=-0.899)$, and unsociable lifestyle $(C C=-0.720)$. It is interesting that people of this sub-cluster are not very good in pro-law attitude $(C C=-0.858)$. In other words, pro-danger people do 
not pay attention to strict laws aimed at decreasing accidents and their damages.

The last sub-cluster of risk-oriented people includes driving-oriented people. These people have a pro-driving attitude $(C C=0.843)$, pro-risk attitude $(C C=0.743)$, showy personality $(C C=0.709)$, and pro-sumptuous lifestyle $(C C=0.827)$. In this sub-cluster, pro-government attitude means that while these people are interested in driving, they count on the government as the organization that has to solve the problems that are related to vehicle use.

The first sub-cluster of safety-oriented people is called work-oriented people. It consists of workaholic lifestyle $(C C=0.595)$ and pro-law attitude $(C C=$ $0.581)$, but not adventurer personality $(C C=-0.518)$. People of this sub-cluster (who assign most of their time to work) have a time-dissatisfied attitude $(C C=$ $0.409)$.

The second sub-cluster of safety-oriented people is transit-oriented people. They do not have prodriving attitudes $(C C=-0.716)$. The main features of this sub-cluster are rather against the features of driving-oriented people (the fourth sub-cluster of riskoriented people). People of this sub-cluster do not have a pro-risk attitude $(C C=-0.523)$ and showy personality $(C C=-0.601)$. The other main feature of this sub-cluster is unsociable lifestyle. It is worth mentioning that people of this sub-cluster do not have pro-sumptuous lifestyles $(C C=-0.581)$.

The last sub-cluster of safety-oriented people, which is visible in the last column of Table 8 , is vitality-oriented people with a lively lifestyle $(C C=$ 1.017). The main features of this sub-cluster are protransit attitude $(C C=0.562)$, no pro-risk attitude $(C C=-0.673)$, and no procrastinator personality $(C C=-0.826)$. Furthermore, people of this subcluster do not have pro-risk $(C C=-0.673)$, pronegligence attitude $(C C=-0.526)$, pro-sumptuous lifestyle $(C C=-0.759)$, nor showy personality $(C C=$ $-0.608)$ and are rather patient $(C C=0.570)$. The final structure of this clustering is shown in Figure 2.
The comparisons of the relative frequency of socio-demographic characteristics of sub-clusters are shown in Figure 3. This figure is a multidimensional chart whose vertical and horizontal axes show the sub-clusters and the percentage of relative frequency, respectively. This figure consists of four parts: gender, marital status, age, and education. According to Figure 3(a), the male-to-female ratio in the depressionoriented cluster is larger than that in other clusters. The relative frequency of women in the motorcycleoriented cluster is influenced by the fact that it is illegal for women to ride a motorcycle in Iran. In contrast, there is an increase in the relative frequency of women in danger-oriented cluster than that in other clusters. According to Figure 3(b), most of the people in dangeroriented and driving-oriented clusters are single, while transit-oriented and vitality-oriented people are often married. It is interesting that the frequency of divorced or widowed people is higher among danger-oriented and work-oriented clusters. According to Figure 3(c), danger-oriented and driving-oriented people are usually 18 to 30 years old, while transit-oriented and vitalityoriented people are often more than 40 years old. Figure 3(d) compares the education of individuals. It shows that depression-oriented people have low education levels (no academic degree and diploma), while vitality-oriented people have higher education levels (bachelor and further).

\subsection{Correlation analysis}

In this section, the results of correlation analysis between vehicle type and each group of individuals specified through clustering are studied. Table 9 shows the result of this analysis for the vehicle type based on weight and function. In this table, the first and second columns show the position of individuals in each cluster and sub-cluster, respectively. The category of individuals' car is presented in the first row and only the significant correlations are displayed. As shown in Table 9, each of these vehicle types is more attractive to specific groups of individuals, because people of each

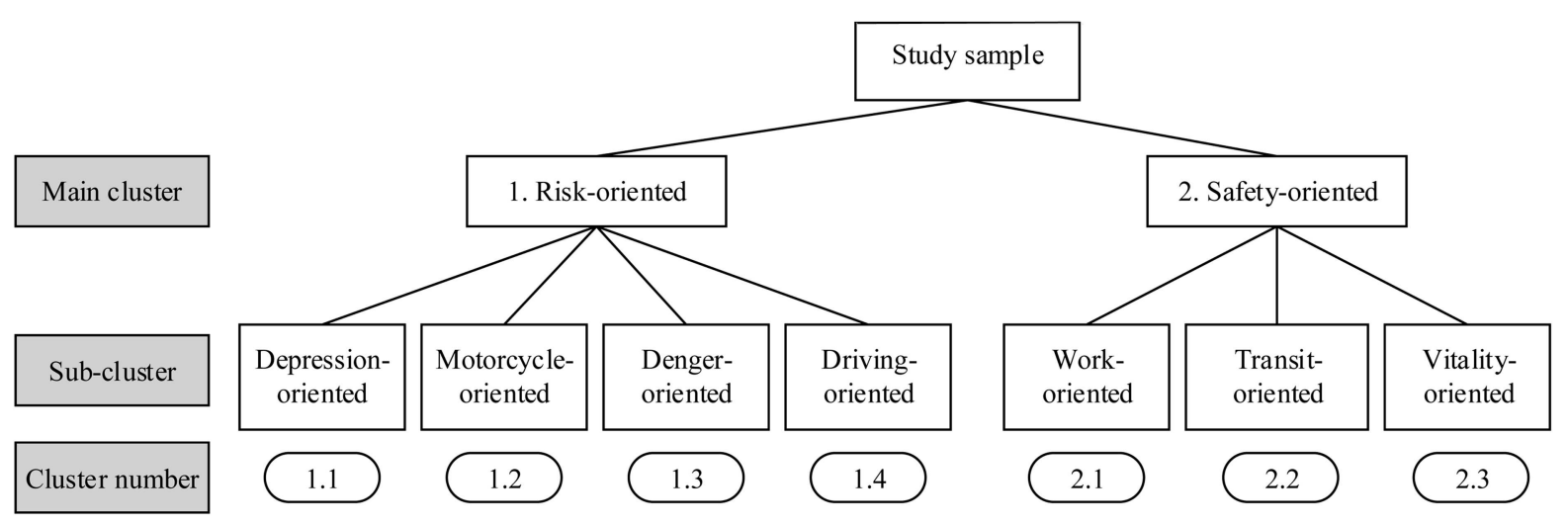

Figure 2. Clustering structure. 


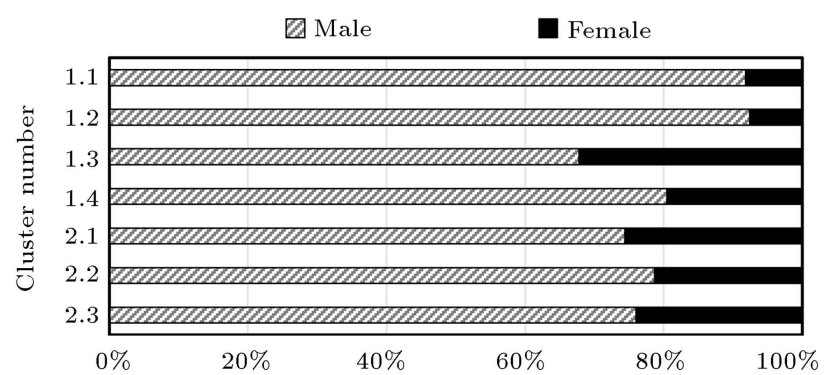

(a) Gender distribution



(c) Age distribution

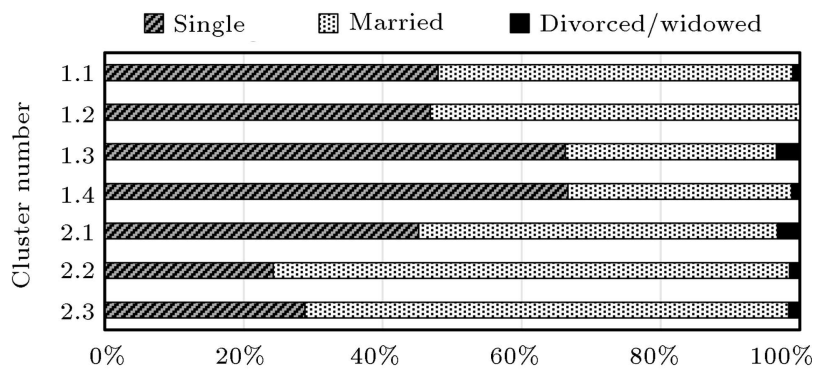

(b) Marital status distribution

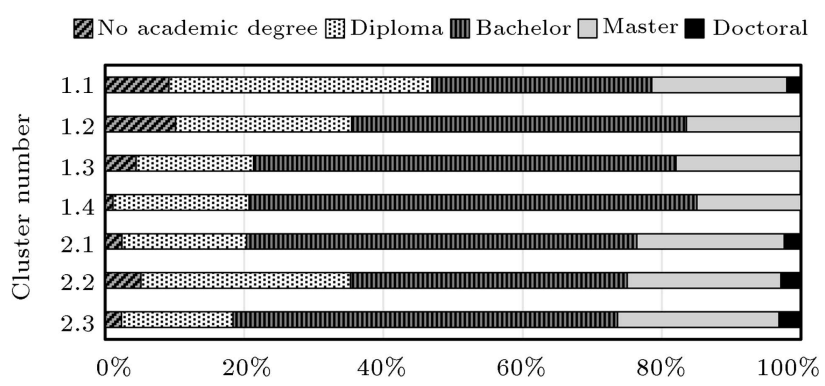

(d) Education distribution

Figure 3. Cluster composition.

Table 9. Correlation analysis results between clusters and type of car.

\begin{tabular}{|c|c|c|c|c|c|c|c|c|}
\hline Main cluster & Sub-cluster & Mini & Compact & Medium & Large & SUV & Pickup & Motorcycle \\
\hline \multirow{4}{*}{$\begin{array}{c}\text { Risk- } \\
\text { oriented }\end{array}$} & Depression-oriented & - & - & - & - & - & $0.091^{*}$ & - \\
\hline & Motorcycle-oriented & $0.116^{* *}$ & - & - & - & $-0.076^{*}$ & - & $0.251^{* *}$ \\
\hline & Danger-oriented & & $0.095^{* *}$ & - & - & - & - & - \\
\hline & Driving-oriented & $-0.098^{* *}$ & - & - & $0.130^{* *}$ & $0.119^{* *}$ & - & - \\
\hline \multirow{3}{*}{$\begin{array}{l}\text { Safety- } \\
\text { oriented }\end{array}$} & Work-oriented & - & - & - & - & $0.080^{*}$ & - & - \\
\hline & Transit-oriented & $0.085^{*}$ & $-0.093^{*}$ & - & - & - & $0.102^{* *}$ & - \\
\hline & Vitality-oriented & - & $0.094^{*}$ & $0.095^{* *}$ & $-0.112^{* *}$ & - & - & $-0.081^{*}$ \\
\hline
\end{tabular}

* Correlation is significant at the 0.05 level (2-tailed). ** Correlation is significant at the 0.01 level (2-tailed).

sub-cluster have different attitudes, personalities, and lifestyles. In addition, numerous results are derived from the combination between Tables 8 and 9 and some of them are as follows:

- Mini: The mini cars have a positive correlation with motorcycle-oriented $(r=0.116)$ and transitoriented people $(r=0.085)$. Motorcycle-oriented people characterized by a pro-negligence attitude and a non-workaholic lifestyle may not be in a proper financial position; in addition, transit-oriented people who tend to drive less and have an unsociable lifestyle will probably select smaller cars. However, driving-oriented people hardly drive mini cars $(r=-0.098)$;

- Compact: Compact car drivers mostly belong to danger-oriented and vitality-oriented clusters.
Transit-oriented people are less likely to drive these cars. Those with a danger-oriented approach share many similarities with those who have a vitalityoriented approach. They are both sociable and against individualism and unlike transit-oriented people, these two groups of people tend to drive bigger cars than mini ones;

- Medium: Those with a vitality-oriented approach who do not have a showy and pro-sumptuous lifestyle are the only ones who tend to drive medium cars more than any other type of car. Vitalityoriented people are mostly educated people who procrastinate less. This is similar to the result obtained by Choo and Mokhtarian [5] who stated that organizers would tend to drive mid-sized cars. It is important to note that almost the same ques- 
tions were asked through both surveys to study the personality of organizers and procrastinators and the difference in nomenclature resulted from the difference in other effective questions for exploring the latent variable;

- Large: Driving-oriented people who mainly have a showy and adventurer personality and follow a prosumptuous lifestyle tend to drive large cars that show wealth and power more than other types, and vitality-oriented people who do not follow a prosumptuous lifestyle are the only ones who are less interested in driving these cars. The preceding result is in agreement with the finding of Choo and Mokhtarian [5] who revealed the direct correlation between the status-seeking lifestyle and luxury and sports cars;

- SUV: SUV car drivers mostly tend to be drivingoriented and work-oriented people. They are showy and have a pro-sumptuous lifestyle. Furthermore, the size and operation of this type of car are suitable for adventurous driving-oriented people and for drivers with a work-oriented approach who are displeased with travel time. It is also important to note that unlike these two groups, motorcycleoriented drivers who tend to drive mini vehicles are less interested in driving SUV;

- Pickup: Today in Iran, pickups are mostly used for shipment and freight delivery. Pickup driving, which is an example of service sector job, is reckoned to be a low-class job in Iran and its drivers are mostly transit-oriented and depressionoriented people. Transit-oriented people who do not enjoy driving include the married, old people, and depression-oriented people with a less lively lifestyle;

- Motorcycle: Motorcycle drivers are mostly those who have a motorcycle-oriented approach and are pro-risk and pro-negligence oriented. Therefore, vitality-oriented people who are less pro-risk and pro-negligence oriented are the only ones who do not tend to drive motorcycles.

With a closer look into the correlations of vehicle type and transportation attitudes, safety attitudes, personality, and lifestyle, the results of the correlation analysis for clustering the vehicles based on fuel economy level, production country, vehicle emission, and vintage are shown in Table 10 . In this table, the results of correlation analysis for one category of dummy variables (in Table 2) can be seen, and the results of the other categories are the opposite. Afterward, the results of this analysis are interpreted:

- Low emission: Low-emission cars have a positive correlation with driving-oriented and work-oriented people. It is interesting that both of these groups have healthy lifestyles, whereas depression-oriented people who live unhealthy lifestyles and have a progovernment approach are the only ones who have a negative correlation with low-emission vehicles;

- Low consumption: Motorcycle drivers are the only ones who have a positive correlation with lowconsumption vehicles. These groups of people who have a low time-dissatisfied attitude mostly tend to drive motorcycles and mini cars, which have a low fuel economy level (Table 9). On the contrary, driving-oriented and transit-oriented people mostly choose cars with a high fuel consumption rate. As mentioned earlier, pro-sumptuous people tend to drive large cars and SUVs, and transit-oriented people tend to drive pickups that are not fuelefficient cars;

- New vehicle: There is a significant negative correlation between new vehicles and depression-oriented people only. This group of people has lack of vitality and prefer old vehicles more than new ones;

Table 10. Correlation results between clusters and vehicle/driver classes.

\begin{tabular}{|c|c|c|c|c|c|c|c|}
\hline $\begin{array}{l}\text { Main } \\
\text { cluster }\end{array}$ & Sub-cluster & $\begin{array}{c}\text { Low } \\
\text { emission }\end{array}$ & $\begin{array}{c}\text { Low } \\
\text { consumption }\end{array}$ & $\begin{array}{c}\text { New } \\
\text { vehicle }\end{array}$ & $\begin{array}{l}\text { Foreign } \\
\text { vehicle }\end{array}$ & $\begin{array}{c}\text { Driver with } \\
\text { damage } \\
\text { accident }\end{array}$ & $\begin{array}{c}\text { Driver with } \\
\text { injury } \\
\text { accident }\end{array}$ \\
\hline \multirow{4}{*}{ Risk-oriented } & Depression-oriented & $-0.080^{*}$ & & $-0.096^{* *}$ & - & - & - \\
\hline & Motorcycle-oriented & - & $0.106^{* *}$ & - & $-0.076 *$ & - & $0.091^{*}$ \\
\hline & Danger-oriented & - & - & - & - & $0.103^{* *}$ & - \\
\hline & Driving-oriented & $0.119^{* *}$ & $-0.109^{* *}$ & - & $0.147^{* *}$ & - & - \\
\hline \multirow{3}{*}{ Safety-oriented } & Work-oriented & $0.101^{* *}$ & - & - & $0.085^{*}$ & - & - \\
\hline & Transit-oriented & - & $-0.073^{*}$ & - & - & - & - \\
\hline & Vitality-oriented & - & - & - & $-0.146^{* *}$ & - & - \\
\hline
\end{tabular}

* Correlation is significant at the 0.05 level (2-tailed). ** Correlation is significant at the 0.01 level (2-tailed). 
- Foreign vehicle: Driving-oriented and work-oriented people, who are both showy and live a healthy and pro-sumptuous lifestyle, mostly choose foreign vehicles. However, motorcycle-oriented and vitalityoriented people tend to drive domestic vehicles. It is also interesting to note that most of the existing motorcycles in Iran are domestic; however, large cars and SUVs are foreign cars;

- Driver with damage accident: The only groups of individuals who have a significant correlation with drivers and experience damaging accidents are danger-oriented people who are part of risk-oriented people. This group of people has high pro-risk and low pro-law attitudes. This finding is in line with the theory of self-selection that was presented by Van Wee [54]. According to Figure 3, women and youths (18 to 30 ) have a higher relative frequency in this category;

- Driver with injury accident: Drivers that have experienced injury accidents are mostly motorcycleoriented drivers who have a danger-oriented approach. According to Table 9, this group of drivers not only drives motorcycles and mini cars that are more vulnerable in accidents and motor vehicle collisions, but also has a pro-negligence safety attitude. Pro-negligence safety attitude means that the driver neglects the fastening of seatbelt or observing the safe distance control with the front vehicle.

\section{Discussion and conclusion}

The aim of this study was to achieve a deeper understanding of the correlation between vehicle type and subjective factors, i.e., transportation attitudes, safety attitudes, personality, and lifestyle, for the first time in Iran. Due to the behavioral, cultural, and domestic characteristics of Iranians, a specific questionnaire was designed to learn about transportation and safety attitudes, personality, and lifestyle, which are the key points for implementing this study. After collecting data from Tehran residents, statistical analyses were used to examine the correlation between subjective variables and vehicle type. These statistical analyses are made of two main stages:

1. Applying factor analysis to determine the latent variables;

2. Clustering individuals by using those latent variables through the application of cluster analysis.

In this study, based on weight and performance, vehicle types are categorized into seven: mini, compact, medium, large, Sport Utility Vehicle (SUV), pickup, and motorcycle. Furthermore, more classification schemes are given based on fuel economy level, pro- duction country, vehicle emission, vintage, and motor vehicle collisions.

One of the results of this paper is a two-level clustering where the maximum observed difference at the first level was the difference in viewpoints on safety. In this manner, individuals were divided into two main clusters: risk-oriented and safety-oriented. To make the effect of other latent factors clear, people of each cluster were divided into sub-clusters. At the second level, risk-oriented people were divided into four sub-clusters including depression-oriented, motorcycleoriented, danger-oriented, and driving-oriented people, and safety-oriented people were divided into three sub-clusters including work-oriented, transit-oriented, and vitality-oriented people. Each of these identified sub-clusters was characterized by many differences in lifestyle, personality, transportation, and safety attitudes.

The applied correlation analysis for this survey showed that there was a significant correlation between each of these identified clusters and vehicle types. The most popular vehicles for each of these clusters are as follows: pickup for depression-oriented people, motorcycle and mini cars for motorcycle-oriented people, compact cars for risk-oriented people, large cars and SUV for driving-oriented people, SUV for work-oriented people, pickup and mini cars for transitoriented people, and compact and medium cars for vitality-oriented people.

The purpose of this study was to analyze and describe the current status. In this regard, the comparison of results and the actual situation would be valuable and beneficial. For example, our results displayed pickups with a higher probability, which are usually chosen by depression-oriented people. As mentioned, pickups in Iran were used only for the purpose of work and shipment and only the low-income people of the community chose this type of vehicles. Therefore, this positive correlation between the depression-oriented sub-cluster and the pickup corresponds to reality.

As another example, the results represented that driving-oriented people had a significantly positive correlation with large and foreign vehicles. It should be noted that a notable proportion of large and foreign vehicles in the database belongs to the BMW manufacturer. It is clear that this brand in the world, especially in Iran, is a symbol of luxury vehicles for car lovers. This observation was consistent with our results, which showed that those with more tendencies to driving and using foreign vehicles were more likely to choose a large vehicle.

Furthermore, this study reveals a significant correlation between motor vehicle collision of each vehicle type and groups of individuals who differ in attitude, personality, and lifestyle. It is interesting to note that danger-oriented people, who have a pro-risk at- 
titude, and motorcycle-oriented people, who have a pro-negligence attitude, have a direct correlation with damage and injury accidents, respectively.

Descriptive statistical analyses were carried out to conduct this pioneering study on vehicle type choice in Iran. For further research on this topic, developing a discrete choice model (e.g., Integrated Choice and Latent Variable (ICLV) model) is recommended along with a closer look into the correlation between subjective variables and vehicle type. Besides, paying attention to socio-economic factors, personal attribute, occupation, life cycle, and built environment is also recommended to ensure a better perception of how people choose their vehicle types.

Previous studies have shown a theory of selfselection effect based on safety attitudes in choosing the vehicle type [54]; this has not been analyzed. Exploring this self-selection effect could make the transportation behavior of individuals and their vehicle type choice clearer.

\section{Acknowledgment}

The authors would like to express their sincere gratitude to the Iran National Science Foundation (INSF) for their kind cooperation with the Institute for Transportation Studies and Research (ITSR) and their financial support.

\section{References}

1. McCarthy, P.S. and Tay, R.S. "New vehicle consumption and fuel efficiency: A nested logit approach", Transportation Research Part E: Logistics and Transportation Review, 34(1), pp. 39-51 (1998).

2. Bhat, C.R., Sen, S., and Eluru, N. "The impact of demographics, built environment attributes, vehicle characteristics, and gasoline prices on household vehicle holdings and use", Transportation Research Part B: Methodological, 43(1), pp. 1-18 (2009).

3. Liu, Y., Tremblay, J.-M., and Cirillo, C. "An integrated model for discrete and continuous decisions with application to vehicle ownership, type and usage choices", Transportation Research Part A: Policy and Practice, 69, pp. 315-328 (2014).

4. Van Acker, V., Spatial and Social Variations in Travel Behaviour: Incorporating Lifestyles and Attitudes Into Travel Behaviour-Land Use Interaction Research, Ghent University (2010).

5. Choo, S. and Mokhtarian, P.L. "What type of vehicle do people drive? The role of attitude and lifestyle in influencing vehicle type choice", Transportation Research Part A: Policy and Practice, 38(3), pp. 201222 (2004).

6. Chamberlain, C. "A preliminary model of auto choice by class of car: aggregate state data", unpublished discussion paper, Transportation Systems Center, U.S. Department of Transportation (1974).

7. Huang, H., Chin, H.C., and Haque, M.M. "Severity of driver injury and vehicle damage in traffic crashes at intersections: a Bayesian hierarchical analysis", Accident Analysis \& Prevention, 40(1) pp. 45-54 (2008).

8. Delkhosh, M., Saadat-Foumani, M., and Rostami, P. "Optimization of power train and control strategy of hybrid electric vehicles", Scientia Iranica, 22(5), pp. 1842-1854 (2015).

9. Poorzahedy, H., Aghababazadeh, B., and Babazadeh, A. "Dynamic network pricing to contain urban air pollution in stochastic environment", Scientia Iranica., Transactions A, Civil Engineering, 23(5), p. 2005 (2016).

10. Iranian Legal Medicine Organization Official Website, 2017, http://www.lmo.ir, (accessed 5.12.17).

11. Top 20 countries in primary energy consumption in 2016, https://www.statista.com/statistics/263455 /primary-energy-consumption-of-selected-countries/, (accessed 19.12.17).

12. Pollution Index (2016). https://www.numbeo.com /pollution/rankings.jsp?title $=2016$, $($ accessed 19.12.17).

13. Eluru, N., Bhat, C.R., Pendyala, R.M., and Konduri, K.C. "A joint flexible econometric model system of household residential location and vehicle fleet composition/usage choices", Transportation, 37(4), pp. 603626 (2010).

14. Mohammadian, A. and Miller, E. "Empirical investigation of household vehicle type choice decisions", Transportation Research Record: Journal of the Transportation Research Board, 1854, pp. 99-106 (2003).

15. Beck, M.J., Rose, J.M., and Hensher, D.A. "Environmental attitudes and emissions charging: An example of policy implications for vehicle choice", Transportation Research Part A: Policy and Practice, 50, pp. 171-182 (2013).

16. Zhang, J., Fujiwara, A., and Kuwano, M. "Modeling group decision-making mechanisms in household travel behavior: theories and an application", Journal of the Eastern Asia Society for Transportation Studies, 7, pp. 654-669 (2007).

17. Peters, A., de Haan, P., and Scholz, R.W. "Understanding car-buying behavior: psychological determinants of energy efficiency and practical implications", International Journal of Sustainable Transportation, 9(1), pp. 59-72 (2015).

18. Federal Highway Administration "1995 NPTS Early Results Report”, Publication No. FHWA-PL-97-028, US Department of Transportation, Federal Highway Administration, Washington, DC (1997).

19. Lerner, M.O., Hickey, S., Dulla, R., and Holmes, J. "Gasoline consumption model", I, Final report (No. PB-256024), Energy and Environmental Analysis, Inc., Arlington, VA (USA) (1975). 
20. Ayres, R., Dogget, R.M., Dussec, D., Humpstone, C., and Lander, J. "Automobile forecasting models", Report prepared by International Research and Technology Corporation for the Office of Technology Assessment, U.S. Congress, Working Paper IRT-446R (1976).

Ayres, R., Landen, J., Humpstone, C., Dussec, D., and Doggett, R. "Automobile forecasting models" (1976).

21. Manski, C.F. and Sherman, L. "An empirical analysis of household choice among motor vehicles", Transportation Research Part A : general, 14(5), pp. 349-366 (1980).

22. Hocherman, I., Prashker, J.N., and Ben-Akiva, M. "Estimation and use of dynamic transaction models of automobile ownership", Transportation Research Record, 944, pp. 134-141, ISSN: 0361-1981 (1983).

23. Mannering, F. and Winston, C. "A dynamic empirical analysis of household vehicle ownership and utilization", The RAND Journal of Economics, 16(2), pp. 215-236 (1985).

24. Golob, T.F., Kim, S., and Ren, W. "How households use different types of vehicles: A structural driver allocation and usage model", Transportation Research Part A: Policy and Practice, 30(2), pp. 103-118 (1996).

25. Wu, G., Yamamoto, T., and Kitamura, R. "Vehicle ownership model that incorporates the causal structure underlying attitudes toward vehicle ownership", Transportation Research Record: Journal of the Transportation Research Board, 1676(1), pp. 61-67 (1999).

26. Mohammadian, A. and Miller, E. "Nested logit models and artificial neural networks for predicting household automobile choices: comparison of performance", Transportation Research Record: Journal of the Transportation Research Board, 1807, pp. 92-100 (2002).

27. Bhat, C.R. and Sen, S. "Household vehicle type holdings and usage: an application of the multiple discretecontinuous extreme value (MDCEV) model", Transportation Research Part B: Methodological, 40(1), pp. 35-53 (2006).

28. Spissu, E., Pinjari, A.R., Pendyala, R.M., and Bhat, C.R. "A copula-based joint multinomial discretecontinuous model of vehicle type choice and miles of travel", Transportation, 36(4), pp. 403-422 (2009).

29. Paleti, R., Eluru, N., Bhat, C., Pendyala, R., Adler, T., and Goulias, K. "Design of comprehensive microsimulator of household vehicle fleet composition, utilization, and evolution", Transportation Research Record: Journal of the Transportation Research Board, 2254(1), pp. 44-57 (2011).

30. Vyas, G., Paleti, R., Bhat, C., Goulias, K., Pendyala, R., Hu, H.-h., Adler, T., and Bahreinian, A. "Joint vehicle holdings, by type and vintage, and primary driver assignment model with application for California", Transportation Research Record: Journal of the Transportation Research Board, 2302, pp. 74-83 (2012).
31. Lave, C.A. and Train, K. "A disaggregate model of auto-type choice", Transportation Research Part A: general, 13(1), pp. 1-9 (1979).

32. Berkovec, J. "Forecasting automobile demand using disaggregate choice models", Transportation Research Part B: Methodological, 19(4), pp. 315-329 (1985).

33. Berkovec, J. and Rust, J. "A nested logit model of automobile holdings for one vehicle households", Transportation Research Part B: Methodological, 19(4), pp. 275-285 (1985).

34. Cao, X., Mokhtarian, P.L., and Handy, S.L. "Neighborhood design and vehicle type choice: Evidence from Northern California", Transportation Research Part D: Transport and Environment, 11(2), pp. 133-145 (2006).

35. Potoglou, D. "Vehicle-type choice and neighbourhood characteristics: An empirical study of Hamilton, Canada", Transportation Research Part D: Transport and Environment, 13(3), pp. 177-186 (2008).

36. Paleti, R., Bhat, C., Pendyala, R., and Goulias, K. "Modeling of household vehicle type choice accommodating spatial dependence effects", Transportation Research Record: Journal of the Transportation Research Board, 2343, pp. 86-94 (2013).

37. Gärling, T., Gillholm, R., and Gärling, A. "Reintroducing attitude theory in travel behavior research: The validity of an interactive interview procedure to predict car use", Transportation, 25(2), pp. 129-146 (1998).

38. Salomon, I. and Ben-Akiva, M. "The use of the lifestyle concept in travel demand models", Environment and Planning A, 15(5), pp. 623-638 (1983).

39. Wachs, M., Transportation for the Elderly: Changing Lifestyles, Changing Needs, University of California Press (1979).

40. Ulleberg, P. and Rundmo, T. "Risk-taking attitudes among young drivers: The psychometric qualities and dimensionality of an instrument to measure young drivers' risk-taking attitudes", Scandinavian Journal of Psychology, 43(3), pp. 227-237 (2002).

41. Chen, C.-F. "Personality, safety attitudes and risky driving behaviors-evidence from young Taiwanese motorcyclists", Accident Analysis \& Prevention, 41(5), pp. 963-968 (2009).

42. Shock, N.W. "Normal human aging: The Baltimore longitudinal study of aging", US Department of Health and Human Services, Public Health Service, National Institutes of Health, National Institute on Aging, Gerontology Research Center (1984).

43. Eysenck, H.J. "A model for personality", Springer Science \& Business Media (2012).

44. Redmond, L., Identifying and Analyzing TravelRelated Attitudinal, Personality, and Lifestyle Clusters in the San Francisco Bay Area, Institute of Transportation Studies (2000).

45. Mokhtarian, P.L., Salomon, I., and Redmond, L.S. "Understanding the demand for travel: It's not 
purely'derived", Innovation: The European Journal of Social Science Research, 14(4), pp. 355-380 (2001).

46. Tehran Municipality Official Website (2016), http://atlas.tehran.ir (accessed 21.11.16).

47. Statistical Center of Iran Official Website (2017), https://www.amar.org.ir (accessed 5.12.17).

48. Potoglou, D. and Kanaroglou, P.S. "Modelling car ownership in urban areas: a case study of Hamilton, Canada", Journal of Transport Geography, 16(1), pp. 42-54 (2008).

49. Vehicle Size and Weight: Bigger Heavier Vehicles Protect Their Occupants Better. Insurance Institute for Highway Safety Website (2017). http://www.iihs.org/iihs/topics/t/vehicle-size-andweight/fatalityfacts/passenge r-vehicles (accessed 18.11.17)

50. Dashtestaninejad, H., Vaziri, M., and Timmermans, H. "Rural location-based activity generation: a case study of Iran villages", Transportation Letters, 8(3), pp. 131-139 (2016).

51. Brown, T.A., Confirmatory Factor Analysis for Applied Research, Guilford Publications (2014).

52. Costello, A.B. and Osborne, J.W. "Best practices in exploratory factor analysis: Four recommendations for getting the most from your analysis", Practical Assessment, Research \& Evaluation, 10(7), pp. 1-9 (2005).

53. Kianfar, K., Ahadzadeh Namin, M., Alam Tabriz, A., Najafi, E., and Hosseinzadeh Lotfi, F. "Hybrid cluster and data envelopment analysis with interval data", Scientia Iranica, 25(5), pp. 2904-2911 (2018).

54. Van Wee, B. "Self-selection: A key to a better understanding of location choices, travel behaviour and transport externalities?", Transport Reviews, 29(3), pp. 279-292 (2009).

\section{Biographies}

Ali Mohammadi received his BS in Civil Engineering from Isfahan University of Technology, Isfahan, Iran in 2011 and his MS in Civil Engineering from Sharif University of Technology, Tehran, Iran in 2013. He is currently a $\mathrm{PhD}$ candidate at Civil Engineering Department at Sharif University of Technology. His research interests include land-use and travel demand modeling, use of non-motorized modes of travel, and physical health and transportation.

Mohammad Kermanshah received his BS degree in 1974 from Shiraz University, Iran, his MS degree from South Dakota School of Mines \& Technology in USA in 1978, and his PhD degree from the University of Davis, California, USA in 1984. He is now a Professor of Civil Engineering at Sharif University of Technology, Tehran, Iran. His research interests include transportation modeling, urban transportation planning, and transportation demand management. 